\title{
FANTASIAS SEXUAIS - UMA PESQUISA COM UNIVERSITÁRIOS DA ZONA NORTE DO RIO DE JANEIRO
}

\author{
Diva Cristina de Paula Portella ${ }^{1}$; Helena Theodoro Lopes ${ }^{2}$
}

\author{
SEXUAL FANTASIES - A STUDY OF STUDENTS OF THE NORTH ZONE OF RIO \\ DE JANEIRO
}

\begin{abstract}
Resumo: O objetivo do presente estudo foi avaliar similitudes e diferenças na utilização de fantasias sexuais entre homens e mulheres. Foi realizada uma pesquisa de campo, com 376 estudantes universitários, da Zona Norte do Rio de Janeiro, estando a maioria entre a faixa etária de 17 a 25 anos. O instrumento de levantamento de dados foi um questionário com 17 questões. Para a análise estatística utilizou-se o teste Qui-quadrado. Os resultados demonstraram que a fantasia sexual para homens e mulheres faz parte da vida sexual de uma forma global; porém, os homens, a utilizam com maior frequência nas relações extraconjugais. Ambos sentem-se mais à vontade com parceiros fixos para compartilharem suas fantasias sexuais. Já com parceiros eventuais os homens compartilham mais que as mulheres. Verificou-se que ambos buscam com pouca frequência recursos eróticos para as suas fantasias sexuais. Chegou-se à conclusão que os padrões de fantasias sexuais entre homens e mulheres desta amostra são semelhantes, apresentando erotismo e romantismo. Palavras-chave:. Fantasias Sexuais; sexualidade; sexo; mídia
\end{abstract}

\begin{abstract}
This paper addresses the theme of sexual fantasies. The aim of the present work is to assess the similarities and differences between men and women in their performance of sexual fantasies. A field study of 376 students of the North zone of Rio de Janeiro was carried out, their ages ranging from 17 to 25 . The tool for data survey was a questionnaire of 17 questions. The qui-square test method was used for statistic analysis. The results showed that the sexual fantasy is part of both men's and women's lives in a general way, although men use them more frequently in extramarital relations. Both feel comfortable with fixed partners when sharing their sexual fantasies. However, men share more with occasional partners than women. It was observed that both rarely seek erotic devices to accomplish their sexual fantasies. We came to the conclusion that the sexual fantasy patterns of men and women of this sample were similar, both expressing eroticism and romanticism.
\end{abstract} Keywords: Sexual Fantasies; sexuality; sex; media

\footnotetext{
${ }^{1}$ Mestre em Sexologia (UGF/RJ). Psicóloga. Coordenadora e Professora do Curso de PósGraduação em Sexualidade Humana da FAACS - RS . e-mail: diva_ps@uol.com.br

${ }^{2}$ Doutora em Filosofia. Orientadora da Dissertação de Mestrado em Sexologia - UGF/RJ e-mail: helenath@ig.com.br
} 


\section{Introdução}

\section{“A parte mais sensual do corpo e melhor afrodisíaco do mundo é a imaginação"}

(Diane Ackerman, 1996, pág.134)

A sexualidade humana envolve vários aspectos da vida, sejam eles psíquicos, biológicos, políticos, educacionais e religiosos. Entretanto, vivenciar o prazer em suas múltiplas faces, ainda não é comum, devido a décadas de preconceito, patriarcalismo, repressão e à falta de uma educação que não foque a sexualidade apenas nos aspectos médico e preventivo, mas algo essencial para a qualidade de vida humana. $\mathrm{O}$ sexo, apesar de ter passado do nível do "falar sobre sexo" para o "como fazer sexo", ainda é motivo de muitos conflitos psíquicos e relacionais. E a fantasia sexual é o ingrediente essencial para uma relação sexual satisfatória.

O Dicionário do Sexo define fantasias sexuais como sendo "imagens eróticas de relações sexuais, incluindo variações, como encontros homossexuais, sexo grupal ou masoquismo". (GOLDENSON e ANDERSON, 1992, p. 107)

A fantasia sexual é um fator importante para o despertar do desejo, sendo, portanto, fator importante para pesquisa, pois compreender melhor como as pessoas se comportam em relação a esta área é um passo para tentar ajudá-las quando surge a queixa sexual.

A flexibilidade ou rigidez nos valores é importante fator na vivência das fantasias sexuais, levando o indivíduo a experimentar suas fantasias sexuais com mais ou menos prazer ou culpa. Se as fantasias sexuais forem julgadas de forma rígida, é bem provável que os sentimentos despertados com isso sejam negativos à resposta de excitação sexual. Por outro lado, se a fantasia sexual é explorada e apreciada pelas sensações prazerosas que desperta, estará disponível e acessível sempre que se desejar.

Dois elementos são essenciais para a fantasia sexual: a curiosidade e a criatividade.

Sem o uso da criatividade, a sexualidade torna-se rotineira e desinteressante. A inserção do erotismo na intimidade de um casal ajuda a desenvolver o potencial sexual, apontando novos caminhos para o prazer. 


\section{Para HEIMAN e LO PICCOLO}

"As fantasias sexuais são uma forma de reviver situações, comportamentos e experiências prazerosas e agradáveis; servem para expressar a nossa criatividade; e para satisfazer nossos desejos naturais de variar. Variedade, novidade e excitamento são parte das nossas fantasias" (HEIMAN e LO PICCOLO, 1992, p. 78, v. 2).

A fantasia é um elemento essencial, no entanto, para isso é necessário ter um nível bom de cumplicidade entre os parceiros. Ela pode não ser compartilhada por medo da reação do parceiro “(...) quanto maior o conhecimento do próprio corpo e da fantasia do outro, melhor será o desempenho de ambos, já que os dois se tornam experientes em satisfazer os seus desejos" (RIBEIRO, 1995, p.30). Os relacionamentos de longa duração acabam gerando situações ocasionadas pela habituação e o renovar das fantasias é o melhor remédio para a manutenção do desejo sexual.

A mídia e a moda atuam no cotidiano das pessoas, influenciando comportamentos e construindo valores. Se juntado a isso, temos a indústria do sexo, mercado antigo que sobrevivia às escondidas e que, neste século, toma força, movimentando milhões todo ano, influenciando a imaginação e as fantasias sexuais. A modernização dos produtos dos sexshops e a intensidade com que são divulgados pelas revistas femininas e pela internet fazem acreditar que a ida aos sexshops seja importante para incrementar os jogos sexuais, sejam eles individuais ou com o parceiro.

Diante desse contexto, procuramos pesquisar até que pontos homens e mulheres utilizam fantasias sexuais. Assim, o objetivo geral desta pesquisa foi avaliar similitudes e diferenças na utilização de fantasias sexuais entre homens e mulheres.

Pesquisar o comportamento sexual humano é compreender o ser humano em sua plenitude. Com isso, pretende-se promover abertura para novas discussões, neste campo do saber.

\section{Material e Métodos}

Para realizar este trabalho foi feito um levantamento bibliográfico e uma pesquisa de Levantamento ou "Survey". Também pode, a presente pesquisa, ser classificada como comparativa, na medida em que serão avaliadas possíveis diferenças, segundo o gênero. 
Para a análise dos dados, foi utilizado o método quantitativo, tendo como técnica a análise estatística. Para esta análise, foi utilizado o software SPSS, para que os dados fossem avaliados e interpretados, estatisticamente, quanto à frequência, percentagens e às diferenças entre os gêneros.

Utilizou-se a estatística não-paramétrica, através da aplicação do teste do QuiQuadrado, utilizado em pesquisa, e que permite a construção de tabelas de distribuição em frequências simples, bem como o cruzamento de variáveis para se fazer comparações entre frequências. Foi utilizado o nível de significância $\mathrm{p}<0,05$.

Nesta pesquisa foi usado, como instrumento de pesquisa, um questionário autoaplicável, com 17 questões. O questionário visou a obter informações, num primeiro momento, sobre dados pessoais referentes a: sexo, idade, estado civil, nível sócio econômico e religião (questões de 1 a 5). E num segundo momento, investigar a visão dos universitários sobre as fantasias sexuais (questões de 6 a 17).

A amostra, do tipo probabilística, constituiu-se de 376 (trezentos e setenta e seis) estudantes universitários, da Zona Norte do Rio de Janeiro.

\section{Resultados e Discussão}

A amostra consistiu de estudantes universitários, estando ambos os sexos representados de forma semelhante, ou seja, em torno de $50 \%$ para cada.

Quanto à idade, foi constatado que a maioria ficou entre a faixa etária de 17 a 25 anos, tanto para homens como para mulheres, o que representou $74,8 \%$ de mulheres e $68,4 \%$ de homens na amostra. A menor faixa etária, tanto de homens como de mulheres, está entre 31 a 35 anos, provavelmente porque a última englobou um maior número de sujeitos, uma vez que, neste intervalo, não havia limite máximo de idade. A concentração maior é de solteiros, e o estado civil com menor representatividade é o de viúvo(a) com menos de $1 \%$. O fato de a grande maioria ser solteiro deve-se ao fato do maior número de pessoas estar na faixa etária entre 17 a 25 anos.

Quanto à religião a maior concentração referiu-se, a religião católica, representando mais de $50 \%$ do total da amostra, seguida pela religião evangélica, o que confirma dados do IBGE em relação à população brasileira. Interessante observar que os homens, quase duas vezes mais que as mulheres, relatam não possuir religião. 


\section{Aspectos Relacionados ao Uso de Fantasias Sexuais}

\section{- Frequência no Uso das Fantasias Sexuais}

Não foi observada diferença estatística significativa entre os gêneros. Contudo, é importante observar que a concentração da frequência ficou em “Às vezes” e, em seguida, em "Raramente" tanto para homens como para mulheres, totalizando 75,1\% das mulheres e $78,5 \%$ dos homens. A frequência que apresentou uma diferença maior entre homens e mulheres, mas ainda assim não significativa, foi "nunca", onde as mulheres responderam mais do dobro de vezes que os homens.

De acordo com CAVALCANTI e CAVALCANTI (1992), a fantasia erótica é muito importante para a vida sexual. "As pesquisas já demonstraram que homens e mulheres costumam ter de 7 a 40 fantasias sexuais, por dia”. (p.223). No entanto, o resultado desta amostra não foi semelhante aos apresentados por estes autores.

Os resultados do presente trabalho, no entanto, correspondem aos estudos de KOLODNY, MASTERS e JOHNSON (1982, p. 283), que defendem como errônea, a idéia de que as mulheres não têm fantasias sexuais, pois homens e mulheres apresentaram percentual de frequência semelhante.

\section{- Afirmações sobre o que Representa a Fantasia Sexual}

Quando se comparam os níveis de concordância de homens e mulheres sobre o que representa a Fantasia Sexual, em relação às seis afirmativas, aquela que apresenta uma diferença maior é a que diz que "a fantasia sexual é usada mais nas relações extraconjugais". Isso demonstra que, nesta amostra, os homens ainda fazem distinção de mulher-esposa e mulher-amante, não conseguindo ainda visualizar a liberdade sexual que a mulher vive hoje, independente de sua idade ou estado civil. Demonstra que estes homens ainda vivem sob o antigo valor: "mulher de casa é pra isso e mulher da rua é pra aquilo", em que a mulher esposa tem que ser a mãe, a cuidadora, ou seja, separando os papéis de esposa e de amante, como se ambas não pudessem estar numa só, desempenhando os dois papéis. Outra que apresenta uma diferença significativa é a afirmativa 3; pode-se supor que esse resultado, deve-se ao fato do homem, começar as suas experiências eróticas mais cedo, do que as mulheres, pois sua própria educação reforça isso, junto aos estímulos recebidos da mídia. $\mathrm{E}$ também, porque os homens, conforme KINSEY et. all (1953), fantasiam mais durante sua masturbação, do que as mulheres. 


\section{- Utilização de Fantasias Sexuais em Algumas Situações}

Os maiores percentuais, somando-se as frequências (1) e (2), para as mulheres, sobre o momento em que utilizam fantasias, foram: "Durante a relação sexual propriamente dita" e “Durante as preliminares com o parceiro", representado por 39,2\% e 38,2\% respectivamente. Esta amostra está de acordo, ainda que em percentual menor, com a pesquisa realizada por FISCHER (1978), em que mais de 75\% das mulheres indicaram que têm uma fantasia ou imagem que retorna ocasionalmente, durante a relação sexual.

E para os homens, somando as frequências (1) e (2), houve semelhança nos resultados: o mais representativo foi "Durante as preliminares com a parceira" com 46,4\%, seguido por "Quando algo ou alguém me desperta interesse" com 36,7\%, "Durante a relação sexual propriamente dita" com 36.4\% e "Quando eu me masturbo sozinho", com 35\%.

Comparando os resultados entre homens e mulheres, constatou-se diferença estatística significativa nas seguintes afirmativas: quando o momento da utilização da fantasia é "a qualquer hora do dia", os homens apresentaram um percentual maior que as mulheres na frequência “Às vezes”, e as mulheres apresentaram um percentual maior que os homens na frequência "Nunca"; os homens fantasiam mais que as mulheres quando alguém desperta interesse; este resultado demonstra que este comportamento ainda é consequência de anos de repressão em relação a sexualidade que a mulher sofreu.

Quando o momento da fantasia é "durante a masturbação", somando-se as frequências (1) e (2), o resultado é de $11,9 \%$ de mulheres e $35 \%$ de homens, correspondendo às pesquisas de KINSEY et all. (1953), que apontam que as mulheres fantasiam com uma frequência menor que os homens, enquanto se masturbam. Já os homens, em quase todas as suas experiências de masturbação, fazem uso de fantasias sexuais. Contudo, os dados da presente pesquisa ficaram distantes do relatório KINSEY, que mostra um percentual maior: $64 \%$ de mulheres que utilizavam a fantasia sexual na masturbação, para 89\% dos homens (KINSEY et all., 1954:642). Há que se considerar que esses estudos foram feitos na década de 50.

\section{- Busca de Recursos para as Fantasias Sexuais}

Verificou-se que, não houve diferença estatística significativa entre os gêneros. Os homens tiveram um percentual maior que as mulheres, somando-se as freqüências (1) e (2), 
quando a busca está relacionada a: livros e revistas; filme pornográfico; e através da Internet; eles, portanto, demonstram construir suas fantasias sexuais a partir de estímulos visuais com maior freqüência que as mulheres. $\mathrm{O}$ único item em que as mulheres tiveram um percentual maior que os homens ainda que pouco, somando-se as freqüências (1) e (2), foi quando os recursos para as fantasias foram aprendidos com alguém, representando 13,9\% de mulheres e $11,5 \%$ de homens.

Esses resultados demonstram que, nesta amostra, as mulheres ainda estão um pouco tímidas na busca do seu prazer, não correspondendo muito ao que as revistas femininas demonstram: um perfil da mulher liberada, que costuma sair em busca de inovações sexuais. Contudo, há de se considerar que o perfil de mulheres desta amostra é de 74,8\% com idade entre 17 e 25 anos, o que talvez possa justificar a baixa freqüência com que buscam esses recursos.

\section{- Partes do Corpo que mais Despertam Fantasias Sexuais.}

Houve uma diferença estatística significativa, entre os gêneros, relacionada às partes do corpo que mais despertam fantasias sexuais, ou seja: nuca, pescoço, axilas, braços, costas, peitos/seios, orelhas, órgãos genitais, quadril, nádegas, pernas e pés.

As partes do corpo que as mulheres valorizam mais do que os homens, somando-se os itens (1) e (2), são: pescoço (mulheres 81,0\%, homens 69,9\%); costas (mulheres 80,8\%, homens 67,9\%); nuca (mulheres 75,7\%, homens 56,7); braços (mulheres 44,9\%, homens $33,9 \%$ ); E as partes do corpo que os homens valorizam mais do que as mulheres, somando-se os itens (1) e (2), são: nádegas (homens 95,2\%, mulheres 78,1\%); pernas (homens 92\%, mulheres 72,4\%); peitos/seios (homens 91,9\%, mulheres 82,6\%); quadril (homens 80,3\%, mulheres 45,7); os pés (homens 42,7\%, mulheres 31,8\%); e axilas (homens 23,7\%, mulheres $9,6 \%)$.

Na afirmativa: "uma parte mais específica", foram citadas as seguintes partes do corpo: boca, olhos, nariz, dentes, umbigo, ânus, língua, pêlos pubianos, pele, mamilos, unhas, sinais do corpo, sobrancelhas, períneo, tríceps e clitóris. Vale ressaltar que a boca teve um número expressivo em seu percentual, o que vai ao encontro às perspectivas evolucionistas de MORRIS (1974).

Foi observado também que o homem, embora valorize em primeiro lugar os órgãos genitais e as nádegas, ele, 
assim como a mulher, valoriza todo o corpo no despertar das fantasias sexuais, o que não corresponde, nesta amostra, à visão de que, para o homem, o sexo é mais genitalizado do que para a mulher, visto que, ela também apresentou um percentual alto, no que diz respeito aos órgãos genitais, confirmando os estudos de KOLODNY, MASTERS e JOHNSON (1982, p. 285) de que os padrões de fantasias de homens e mulheres são mais semelhantes que diferentes.

\section{- Compartilhamento da Fantasia Sexual.}

Somando-se os itens (1), (2) e (3), os resultados demonstram que, em se tratando de parceiros fixos, mais de $50 \%$ de homens e mulheres compartilham suas fantasias sexuais. Isso mostra que, dentro de uma relação deste tipo, há mais cumplicidade, fator importante no compartilhamento das fantasias.

Os homens compartilham mais suas fantasias sexuais com parceiras eventuais do que as mulheres, o que comprova uma maior liberação masculina, para este tipo de encontro com fins sexuais; entretanto, o número de mulheres que nunca tiveram parceiros eventuais é bem representativo.

Comparando com o compartilhamento com parceiro fixo, em que as mulheres apresentaram um percentual de mais de 50\% (somando-se os itens 1,2 e 3 ) e com parceiro eventual apenas $21,4 \%$, verifica-se que a mulher ainda não se sente totalmente livre para se expor em termos de sexo, quando ainda não tem muita intimidade com seu parceiro. Isso mostra ser reflexo de uma sociedade patriarcal, em que a mulher era criada para ter apenas um homem, o seu marido, e para sempre se relacionar visando "compromisso". Ao se deparar com um parceiro eventual, ela não se afirma enquanto um ser, que tem a mesma liberdade sexual do que o homem. Este, por sua vez, sempre foi criado para chegar em qualquer relacionamento, seja com parceiro fixo ou eventual, com o mito de que ele é que pode tudo, sobre sexo.

\section{- Quem Propõe a Fantasia Sexual}

Observou-se que, para um pouco mais de 50\% de homens e de mulheres, em se tratando de parceiro fixo, tanto um quanto o outro, podem propor fantasias sexuais. Através desta constatação, podemos supor que houve uma mudança nos papéis sociossexuais, pois a mulher se sente mais livre para compartilhar suas fantasias sexuais; já com parceiro eventual, esse índice é menor, porém, os homens ainda representam um percentual maior que as mulheres. 
É interessante notar que 56,6\% das mulheres, na tabela anterior, declararam nunca terem tido parceiros eventuais, e esse número passou para $63,8 \%$ (10\% a mais), nesta questão.

Em se tratando de parceiro eventual, os homens propõem fantasias sexuais num percentual muito maior do que as mulheres. Novamente é importante ressaltar que os homens compartilham mais suas fantasias sexuais com parceiras eventuais do que as mulheres, entretanto, o número de mulheres que nunca tiveram parceiros eventuais é bem representativo, o que provavelmente explica essa diferença.

\section{- Sentimento em Relação à Proposta de Fantasia Sexual para o (a) Parceiro (a) Fixo (a).}

Verificou-se que o sentimento que apresentou diferença estatística entre os gêneros foi o de vergonha, apresentando um percentual maior entre as mulheres. Somando-se os itens (1) e (2) os homens estão representados por apenas 10,2\% e, as mulheres por $20,4 \%$.

Observou-se também que a maioria de homens e mulheres se sente à vontade em compartilhar suas fantasias sexuais com parceiros fixos. Somando-se os itens (1) e (2) os homens estão representados por $79,6 \%$ e, as mulheres por $68 \%$. E os homens têm menos medo do que a parceira fixa vai pensar do que as mulheres.

Mais uma vez esses dados demonstram que, em relação a esta amostra, as mulheres estão conseguindo viver com mais liberdade a sua sexualidade com parceiros fixos.

\section{- Sentimento em Relação à Proposta de Fantasia Sexual para o (a) Parceiro (a) Eventual.}

Verificou-se que as afirmativas que apresentaram diferença estatística significativa entre os gêneros foram: "sinto-me à vontade" e o "sinto vergonha"; a primeira, somando-se os itens (1) e (2), mostra que os homens $(53,15 \%)$ sentem-se mais à vontade que as mulheres $(24,6 \%)$ quando o parceiro é eventual e a segunda, somando-se os itens (1) e (2), mostra que são as mulheres $(44,3 \%)$ que têm mais vergonha nessas situações, do que os homens $(22,9 \%)$.

Comparando estes dados com as percentagens encontradas para parceiros fixos e eventuais e somando-se os itens (1) e (2), os homens se sentem mais à vontade quando a parceiro é fixa $(79,6 \%)$ do que quando é eventual $(53,15 \%)$; as mulheres também, embora a diferença percentual seja bem maior, passando de $68 \%$ para $24,6 \%$, havendo, portanto, uma queda maior entre elas. As mulheres, portanto, sentem-se bem menos à vontade do que os 
homens, quando o parceiro é eventual. Os homens também sentem mais vergonha quando a parceira é eventual (22,9\%), somando-se os itens (1) e (2), do que quando a parceira é fixa $(10,2 \%)$, embora compartilhem mais suas fantasias com parceiras eventuais do que o grupo de mulheres estudado. Mulheres sentem ainda mais vergonha, quando o parceiro é eventual $(44,3 \%)$ do que quando o parceiro é fixo $(20,4 \%)$.

O resultado desta amostra não condiz com a imagem que as revistas femininas passam, a da mulher liberal, sedutora, que estimula e/ou realiza fantasias sexuais, disponível, que sabe tudo sobre sexo, o que acaba dificultando a relação de gênero.

\section{- Avaliação das Situações em que as Fantasias Sexuais são Criadas.}

As mulheres apresentaram os maiores percentuais, na avaliação "normal" nas afirmativas: "Fantasiar com meu (minha) próprio parceiro (a)", "Fazer fantasias sexuais durante as relações sexuais", "Fantasiar durante os jogos sexuais" e "Fantasiar com outra pessoa do sexo oposto". E na avaliação "anormal" nas afirmativas: "Fantasiar com outra pessoa do mesmo sexo", "Fantasiar com objetos" e "Fantasiar com mais de uma pessoa".

Os homens apresentaram os maiores percentuais, na avaliação "normal" nas afirmativas: "Fantasiar com meu (minha) próprio parceiro (a)", "Fazer fantasias sexuais durante as relações sexuais", "Fantasiar com outra pessoa do sexo oposto" e "Fantasiar durante os jogos sexuais". E na avaliação "anormal" nas afirmativas: "Fantasiar com outra pessoa do mesmo sexo", "Fantasiar com objetos" e "Fantasiar nos mais diversos momentos do dia".

É importante ressaltar as diferenças estatísticas significativas entre os gêneros: as mulheres apresentaram maior percentual de "aversão", ao fazer fantasias durante suas masturbações, em fantasiar com mais de uma pessoa e em fantasiar com objetos, do que os homens. E as mulheres, também foram mais indiferentes, do que os homens, em fantasiar com objetos. 


\section{Aspectos Relacionados aos Tipos e Aspectos de Fantasias Sexuais}

\section{- Visita a Lugares para Compra de Produtos para Estimular e/ou Colocar em Prática as}

Fantasias sexuais.

Não foi observada diferença estatística significativa entre os gêneros. Os homens demonstraram visitar mais os sexshops virtuais do que as mulheres, mas ainda sim, ambos apresentam um percentual muito baixo para um mercado em expansão. Esta amostra não condiz com os dados da Associação Brasileira de Empresas do Mercado Erótico (Abeme) que demonstra que $70 \%$ de frequentadores de sexshops são mulheres, que elas representaram $50 \%$ dos visitantes da Feira Erótica em 2004 e que esse mercado movimenta R \$ 700 milhões por ano no Brasil (Revista Marie Claire). É interessante observar que ambos em percentual maior utilizam outros lugares para comprar seus produtos. Dentre esses lugares, os mais citados foram lojas de lingerie, em seguida supermercado, lojas de variedades e livraria ou banca de jornal e por último, farmácia, motéis e vendedores autônomos.

\section{- Qualificação dos Produtos e Serviços que Estimulam e/ou Colocam em Prática a Fantasia Sexual.}

Dos 16 produtos/serviços, foram selecionados os 5 que obtiveram uma qualificação melhor para ambos os gêneros, somando-se os itens (1) e (2):

As mulheres qualificaram, com alto percentual, os estímulos visuais, olfativos, táteis, gustativos e auditivos. Os homens também qualificaram, com alto percentual os estímulos, colocando o estímulo auditivo em percentual menor, $58,2 \%$, somando-se os itens (1) e (2).

As mulheres se preocupam mais em vestir roupas sensuais para seus parceiros para estimular as fantasias sexuais, do que os homens. Pode-se dizer que é o resultado do investimento da indústria da moda e da beleza, direcionado ao público feminino. E conforme SUPLICY (1985), a idéia de que a mulher sempre tem que se preocupar em estar atrativa para seu parceiro continua, a ideologia não muda: "segure seu homem".

Entretanto, embora o investimento da moda, da mídia e do mercado da beleza direcionado ao público masculino ainda não tenha o mesmo apelo que o feminino, as mulheres (64\%, somando-se os itens 1 e 2) apresentaram um percentual significativo na qualificação de roupas sensuais para os homens. E os homens $(58,3 \%$, somando-se os itens 1 e 2) também 
apresentaram um percentual significativo na qualificação de roupas sensuais para eles, mostrando uma mudança significativa no seu papel sociossexual. $\mathrm{O}$ resultado corresponde à visão de FRIDAY (1994), pois demonstra que o homem está se sentindo encorajado a buscar a beleza, mas, especificamente aqui, através do erotismo. Conforme SERAPIÃO (1997), o consumo de produtos ajuda a melhorar as condições de atratividade sexual. E melhorando a atratividade sexual, estimula-se as fantasias sexuais.

Na afirmativa "outros", foram citados os seguintes produtos: calcinha comestível, gelo, algema e camisinhas com cheiro e gosto.

\section{- Utilização de Recursos nas Fantasias Sexuais.}

Os resultados demonstraram que os homens são mais visuais que as mulheres, mas a diferença não é significativa.

Somando - se os itens (1) e (2), verificou-se que as mulheres usam mais roupas íntimas sexys, fantasiam mais cenas tomando banho, fantasiam, mais que os homens, cenas com palavras românticas, cenas em que estejam fazendo strip-tease, com uso de sapato alto. Os homens, comparados às mulheres, assistem mais filmes eróticos, acessam mais sites eróticos, fantasiam mais com sexo em grupo, com cenas de prostituição, com cenas em que ele (a) esteja fazendo strip-tease, assistindo pessoas transando, com relações sexuais com estranhos, e em pessoas famosas.

Verificou-se também que as mulheres fantasiam mais com cenas românticas do que os homens, entretanto, somados os itens (1), (2) e (3), ambos apresentam percentuais altos, 83\% e $75,7 \%$, respectivamente.

Constatou-se que ambos apresentaram percentuais semelhantes no item (1) quanto à fantasia em que se está batendo no parceiro, mas apresentam diferença significativa nos itens (3) e (4). Novamente, ambos apresentaram percentuais semelhantes no item (1), quanto à fantasia com chicote; no entanto, as mulheres apresentaram percentual maior no item (3), correspondendo aos estudos de FRIDAY (1994), pois as fantasias sádicas, por parte das mulheres, estão no mesmo nível percentual dos homens, o que ela denomina de "inversão de papéis", mas que a nosso ver, está havendo uma maior igualdade entre os gêneros. 


\section{Conclusões}

A realização desta Dissertação trouxe a oportunidade de conhecermos um pouco mais da sexualidade humana, dentro de um aspecto ainda pouco pesquisado, como as Fantasias Sexuais. Talvez o fato de ser pouco pesquisada, pelo menos num contexto mais contemporâneo, possa ser a tradução de uma Educação Sexual que ainda privilegie a prevenção e as patologias e afinal somos frutos deste contexto sócio-cultural.

Confirmou-se que existem vários motivos que levam homens e mulheres a fantasiarem, avaliando-se que tal prática faz parte da vida sexual de uma forma global, porém, os homens fantasiam mais em suas relações extra-conjugais. Isso nos faz crer que a maioria dos homens destra amostra ainda não consegue visualizar a liberdade sexual que a mulher vive hoje, vivendo sob antigos valores, demonstrando que fazem a velha distinção "mulher de casa" e "mulher da rua", reflexo do modelo construído pela prática médica higienista no Brasil da "mulher-mãe", cuidadora do lar e dos filhos.

Verificou-se que ambos os gêneros utilizam as fantasias sexuais predominantemente nas relações sexuais, mostrando limitações na produção de fantasias sexuais como aprendizagem para a vida sexual.

A busca de recursos para a fantasia sexual é pequena, não correspondendo ao que as revistas femininas demonstram: um perfil da mulher liberada, que costuma sair em busca de inovações sexuais. Aqui, as mulheres se apresentam tímidas, na busca do seu prazer.

A compreensão do sexo ainda se dá de forma genitalizada, para ambos os sexos, devido à preferência, de ambos, nos resultados, sendo reflexo de uma sociedade em que os meios de comunicação de massa usam e abusam do corpo e da sensualidade. Ao mesmo tempo, pode-se observar uma significativa mudança na importância dada às várias partes do corpo, para o despertar das fantasias, significando que se caminha para uma visão mais ampla do sexo.

Homens e mulheres se sentem mais à vontade com parceiros fixos, para compartilharem suas fantasias sexuais. Os homens compartilham mais suas fantasias com parceiros eventuais do que as mulheres, refletindo as consequências de uma sociedade patriarcal, em que a mulher tinha uma educação mais repressora do que o homem, sendo criada para ter apenas um homem, o seu marido e para sempre se relacionar visando "compromisso". Assim, quando ela se depara com um parceiro eventual, não se afirma enquanto um ser que tem a mesma liberdade sexual do que o homem, enquanto o homem 
sempre foi criado para chegar em qualquer relacionamento, seja com parceiro fixo ou eventual, com o mito de que ele é que sabe tudo sobre sexo.

Considerando o volume de propaganda e reportagens que são publicados principalmente nas revistas femininas e o investimento em lançamentos de produtos eróticos, homens e mulheres desta amostra compram com pouca frequência produtos eróticos, com baixa frequência em sexshops, tendo uma preferência por comprar seus produtos em ouros tipos de lojas. Podemos supor que a sociedade brasileira ainda não vivencia o sexo como uma necessidade como outra qualquer, como comer, dormir, etc.; que o sexo é para fazer, não para falar, para sair às compras.

Os padrões de fantasias sexuais entre homens e mulheres apresentaram-se semelhantes, ressaltando que há uma dose grande de erotismo e romantismo em homens e mulheres, o que demonstra que está aumentando a igualdade nos papéis de gênero. Entretanto, nesta amostra, ambos fazem fantasias sexuais com regular frequência.

Essa pesquisa expressa que a mulher está assumindo um papel novo na esfera sexual, quando se compara com o exercido na sociedade patriarcal; contudo, ela não representa a mulher idealizada pela mídia e pelo sistema consumista. E que esse papel novo, não está sendo construído por nenhum sistema, e sim por ela mesma. Expressa também que o comportamento sexual da sociedade brasileira reflete as consequências de uma sexualidade construída conforme interesses, ora da igreja, ora do Estado, ora penalizando, ora adestrando, através de normas, rotulando e classificando comportamentos, disciplinando o corpo sexual.

Para que os papéis sociossexuais não sejam remodelados ou repaginados, de acordo com interesses de um poder dominante e para que a sexualidade seja vivenciada em sua plenitude, a Educação Sexual deve ser implementada com um enfoque global da sexualidade humana, e não somente abordando temas como: prevenção e DSTs; com uma abordagem reflexiva, e não apenas informativa, promovendo a interação entre os sexos.

Espera-se que esta pesquisa possa contribuir para a elaboração de novas atuações no campo da Sexologia, sejam elas, no campo social, educacional ou clínico. 
Referências Bibliográficas

ACKERMAN, D. Uma história natural dos sentidos. 2 ed. Rio de Janeiro: Bertrand Brasil, 1996.

CAVALCANTI e CAVALCANTI. Tratamento clínico das inadequações sexuais. São Paulo: Roca, 1992.

FISCHER, S. O orgasmo da mulher. São Paulo: Manole, 1978.

FRIDAY, N. Mulheres por cima. As fantasias sexuais das mulheres no pós-feminismo. Rio de Janeiro: Record, 1994.

GIL, M. A.; CASTRO, E. As novas regras do sexo - Até onde vai? Revista Marie Claire. Rio de Janeiro, n. 162, p. 65-74, set./2004.

GOLDENSON, R.; ANDERSON, K. Dicionário do sexo. São Paulo: Summus Editorial, 1992

HEIMAN, J. R. \& LO PICCOLO, J. Descobrindo o prazer uma proposta de crescimento sexual para a mulher. São Paulo: Summus, 1992.

KINSEY, A. C. Sexual behavior in the human male. Philadelphia, USA, W.B.: Sanders Company, 1953.

KINSEY, A. C. et all. Conduta sexual da mulher. Rio de Janeiro: Atheneu, 1954.

KOLODNY, R. C., MASTERS, W. H. e JOHNSON, V. E. Manual de medicina sexual. São Paulo: Manole, 1982.

MORRIS, D. Comportamento íntimo. Rio de Janeiro: José Olympio, 1974.

RIBEIRO, M. Revista Desfile. Rio de Janeiro, n. 307, mai/1995.

SERAPIÃO, J. J. Interdisciplinaridade em sexologia. In: ANDRADE -SILVA, M.C., SERAPIÃO, J. J., JURBERG, P. (Org.). Sexologia: fundamentos para uma visão interdisciplinar. Rio de Janeiro: Ed. Central da Universidade Gama Filho, p. 09-23, 1997.

SUPLICY, M. De Mariazinha a Maria. Petrópolis, RJ: Vozes, 1985.

Bibliografia

ALBUQUERQUE, L. de. Indústria do sexo. Revista Marie Claire. Rio de Janeiro, n. 166, p. $40-45$, jan./2005.

ANNON, J. S. Tratamento comportamental dos problemas sexuais: terapia breve. São Paulo: Manole, 1980.

ARAÚJO, M. L. M. de. História crítica da sexualidade. In: ANDRADE - SILVA, M. C., SERAPIÃO, J. J., JURBERG, P. (Org.). Sexologia: fundamentos para uma visão interdisciplinar. Rio de Janeiro: Ed. Central da Universidade Gama Filho, p. 24-66, 1997. 
BONATO, N. M. da C. Educação [sexual] e sexualidade: o velado e o aparente.

Dissertação de Mestrado. Universidade do Estado do Rio de Janeiro, 1996.

BUITONI, D. S. Imprensa feminina. 2a .. ed. São Paulo: Ática, 1990.

BUSS, D. M. The evolution of desire - strategies of human mating. New Yok: Basic Books, 1994.

CAMPOS, V. As fantasias sexuais segundo as mulheres. In: The Best Big Man

Internacional, ed. 218, ano IX, n. 6-A.

CARDOSO, P. F. As revistas femininas e a abordagem da sexualidade. Dissertação de Mestrado. Universidade Gama Filho. Rio de Janeiro, 1996.

CARIDADE, A. A construção cultural da sexualidade. In: RIBEIRO, M. (org). O prazer e o pensar: orientação sexual para educadores e profissionais de saúde. São Paulo: Gente, p. 13-24, 1999.

CATANIA, A. C. Aprendizagem: comportamento, linguagem e cognição. $4^{\mathrm{a}}$. ed. Porto Alegre: Artes Médicas, 1999.

CAVALCANTI e CAVALCANTI. Tratamento clínico das inadequações sexuais. São Paulo: Roca, 1992.

CHARTAM, R. Guia para o amor sensual. Rio de Janeiro: Artenova, 1974.

COSTA, J. F. Ordem médica e norma familiar. Rio de Janeiro: Graal, 1979.

DEL BIANCO, K.; BERLINK, T. B. - Eles merecem. Revista Marie Claire. Rio de Janeiro: Globo, n. 161, p. 136-140, Ago-2004.

FERRÉS, J. Televisão subliminar: socializando através de comunicações despercebidas. Porto Alegre: ArtMed, 1998.

FLAKE, J. The War Against Pornography. Newsweek, 18 March 1985.

FISCHER - MIRKIN, T. O código do vestir. Rio de Janeiro: Rocco, 2001.

FREUD, S. Escritos criativos e devaneio. In: Edição Standart Brasileira das Obras

Completas de Sigmund Freud. Rio de Janeiro: Imago, 1987 (1908).

FOUCAULT, M. Vigiar e punir: história da violência nas Prisões. Petrópolis: Vozes, 1994.

FOUCAULT, Ml. História da sexualidade I - A vontade de saber. Rio de Janeiro: Graal, 1988.

GAUDÊNCIO, P. "Fantasia sexual: saúde ou doença?” In: COSTA, M. (coord.). Amor e sexualidade. A resolução dos preconceitos. São Paulo: Gente, 1994.

HARVEY, J. Homens de preto. São Paulo: UNESP, 2003.

JURBERG, M. B., JURBERG, P. Atração sexual: principais estímulos segundo a biologia e a psicossociologia. Scentia Sexualis. Rio de Janeiro: Ed. Central da Universidade Gama Filho, v. 4, n. 3, p. 45-73, 1998.

KAPLAN, H. S. Manual ilustrado de terapia sexual. São Paulo: Manoele, 1978.

LADEIRA, A. L.S. A influência da mídia e os estereótipos corporais. Rio de Janeiro. Escola da Comunicação da Universidade Federal do Rio de Janeiro. 2001. Dissertação de Mestrado.

LAKATOS, E. M. \& MARCONI, M. de A . Metodologia científica. São Paulo: Atlas, 1991.

LINTON, R. O indivíduo, a cultura e a sociedade. In: IANNI, O. \& CARDOSO, F.H.

Homem e sociedade. $11^{\mathrm{a}}$ ed. São Paulo: Nacional, 1977.

MARCONDES, C. F. Quem manipula quem? Poder e massa na indústria da cultura e da comunicação no Brasil. 5a . ed. Rio de Janeiro: Vozes,1992. 
MARINHO, A.; CLÉBICAR, T. Jogos de amor. Jornal O Globo, Rio de Janeiro, 5 jun. 2005. Revista, p. 34.

MASTERS, W. H., JOHNSON, V. E., KOLODNY, R. C. Heterossexualidade. Rio de Janeiro: Bertrand Brasil, 1997.

MASTERS, W. H. e JOHNSON, V. E. O vínculo do prazer. São Paulo: Record/Círculo do Livro, 1975.

MONESI, A. É permitido fantasiar. Revista Viver Psicologia, 2001. Ano IX, n.99.

MONTEIRO, D. da M. R. Mulher: feminino plural: mitologia, história e psicanálise. Rio de Janeiro: Rosa dos Tempos, 1992.

NICK, E.; CABRAL, A. Dicionário técnico de psicologia. São Paulo: Cultrix, 1999.

OBJETOS DO DESEJO. Revista Cláudia. Rio de Janeiro, n. 186, out/2004.

ROCHA, E. P. G. A sociedade do sonho: comunicação, cultura e consumo. Rio de Janeiro: Mauad, 1995, p.152.

ROHENKOHI, C. M. F. Brincar para evoluir. Revista Viver Psicologia. São Paulo: 2002.

SANTOS FILHO, j. c. dos. Pesquisa quantitativa versus pesquisa qualitativa: o desafio paradigmático. In: Silvio Sánchez Gamboa (Org.). Pesquisa educacional: quantidade-qualidade. São Paulo: Cortez, p. 13-59, 1995.

SELLTIZ, WRIGHTSMAN L. e COOK S., Métodos de pesquisa nas relações sociais. São Paulo: EPU, 1987.

SILVA, A. C. A sexualidade comparada. Fundamentos bio-antropológicos da terapia sexual. Rio de Janeiro: Achiamé, 1980.

SIMONETTI, C. Mercado de paixões - a influência da mídia no comportamento sexual infantil. In: RIBEIRO, M. (Org.) O prazer e o pensar: orientação sexual para educadores e profissionais de saúde. São Paulo: Gente, p. 69-74, 1999.

STEELE, V. Fetiche: Moda, sexo e poder. Rio de Janeiro: Rocco, 1997.

STEKEL, W. Sexual aberrations: The phenomenon of fetishism in relation to sex. Nova York: Liveright, vol. 1, 1971.

THEODORO, H. Buscando novos caminhos através da educação. In: ANDRADE SILVA, M. C., SERAPIÃO, J. J., JURBERG, P. (Org.).

Sexologia:fundamentos para uma visão interdisciplinar. Rio de Janeiro:

Ed. Central da Universidade Gama Filho, p. 229-248, 1997.

VAN USSEL, J. Repressão sexual. Rio de Janeiro: Nova Fronteira, 1980.

VITIELLO, N. Os meios de comunicação de massa e os adolescentes. Revista Brasileira de Sexualidade Humana, 1993, Vol. 4.

http://camanarede.terra.com.br/ O sexo e as roupas. Acesso em: 03/03/2005.

http://www.erotikafair.com.br/atracao.html. Acesso em: 10/04/2005

http://revistaepoca.globo.com/Epoca/0,6993,EPT639153-1664-1,00.html Acesso em:

$03 / 03 / 2005$

http://www.siteg.com.br Acesso em: 05/05/2005 